\title{
Association of Birth-Weight, Obesity and Family History in the Development of Latent Autoimmune Diabetes in Adults (LADA) and Type 2 Diabetes Mellitus
}

\author{
Shubhangi Verma ${ }^{1}$, Samarth Sharma ${ }^{2}$, Priyadershini Rangari ${ }^{3}$ \\ ${ }^{1} \mathrm{MD}$ (General Medicine), Professor, Department of General Medicine, Dr. PDMMC, Amravati, (Maharashtra), ${ }^{2}$ MD (General Medicine), Assistant Professor, \\ Department of General Medicine,Sri Shankaracharya Medical College, Bhilai, Durg (Chhattisgarh), ${ }^{3} \mathrm{MDS}$ (Oral Medicine and Radiology), Assistant \\ Professor, Department of Dentistry, Sri Shankaracharya Medical College, Bhilai, Durg (Chhattisgarh).
}

\section{Abstract}

Background: A proportion of subjects with adult-onset autoimmune diabetes does not require insulin-therapy at the time of diagnosis and are clinically similar to patients with type 2 Diabetes Mellitus (T2DM). Objectives: The present study was undertaken association of birth-weight, obesity and family history in the development of latent autoimmune diabetes in adults (LADA) and type 2 Diabetes Mellitus. Subjects and Methods: A total of 50 healthy controls, 50 type 2 diabetic and 50 patients with LADA were enrolled. Complete demographic details of all the patients were obtained. Clinical examination of all the patients was carried out and medical history of all the patients was obtained. Detailed medical history and family history of all the patients was recorded separately. A Performa was made and complete anthropometric parameters were recorded. Body mass index (BMI) was calculated. All the results were recorded in Microsoft excel sheet and was analysed by SPSS software. Results: While assessing association of birth-weight in the development of latent autoimmune diabetes in adults (LADA) and type 2 Diabetes Mellitus; it was observed that significantly higher proportion of patients of the diabetic group and the LADA group had low birthweight in comparison to the patients of the control group. While assessing association of family history of diabetes in the development of latent autoimmune diabetes in adults (LADA) and type 2 Diabetes Mellitus; it was observed that significantly higher proportion of patients of the diabetic group and the LADA group had positive family history of diabetes in comparison to the patients of the control group. While assessing association of obesity in the development of latent autoimmune diabetes in adults (LADA) and type 2 Diabetes Mellitus; it was observed that mean BMI of the patients of the diabetic group and the LADA group was significantly higher in comparison to the patients of the control group. Conclusion: Low birth weight, obesity and positive family history of diabetes are important risk factors in the development of latent autoimmune diabetes in adults (LADA) and type II diabetes.

Keywords: Birth weight, Diabetes, latent autoimmune diabetes in adults (LADA), Type 2 Diabetes Mellitus (T2DM).

Corresponding Author: Dr. Samarth Sharma, MD (General Medicine), Assistant Professor,Department of General Medicine,Sri Shankaracharya Medical College, Bhilai, Durg (Chhattisgarh).

Received: December 2019

Accepted: December 2019

\section{Introduction}

Type 1 diabetes mellitus (T1DM) is an autoimmune disease derived from the selective destruction of insulin-secreting $\beta$ cells leading to requirement of insulin therapy. This condition occurs in most cases during childhood or adolescence; however, some patients experience onset in adulthood. A proportion of subjects with adult-onset autoimmune diabetes does not require insulin-therapy at the time of diagnosis and are clinically similar to patients with type 2 Diabetes Mellitus (T2DM). These patients, who were initially thought to be affected by T2DM, are defined as having latent autoimmune diabetes in adults (LADA), a form of autoimmune diabetes, distinct from T1DM that shows an older age of onset and slower progression towards insulin requirement. Diabetes is a more heterogeneous disease than the crude subdivision into type 1 and type 2 Diabetes
Mellitus implies; with a finer classification of diabetes based on differences in pathophysiology, opportunities arise for more accurate assessment of factors influencing disease onset and prognosis. This may allow us to identify etiological factors potentially obscured in analysis of heterogeneous patient groups with different pathogenesis and help us identify modifiable factors which may eventually lead to improved primary prevention. LADA - latent autoimmune diabetes in adults - is a common but understudied form of diabetes with features of both type 1 and type 2 Diabetes Mellitus. ${ }^{[1-3]}$

The three criteria conventionally used to define adult-onset autoimmune diabetes are non-specific; namely, age at diagnosis, autoantibody positivity and need for insulin treatment. Definitions of adult age range from 15 to 30 years, extending to all ages or up to 70 years. Even children aged less than 15 years with phenotypic Type 2 Diabetes Mellitus 
can have DAA and would be designated autoimmune diabetes. Autoantibody criteria lack specificity because they are based on autoantibodies associated with childhood-onset Type 1 diabetes, which lack $100 \%$ specificity, even in the best laboratories. ${ }^{[4]}$

Even though it may take up to 12 years until beta-cell failure occurs in some patients, impairments in the beta-cell response to intravenous glucose and glucagon can be detected at diagnosis of diabetes. Consequently, LADA is not a latent disease; therefore, autoimmune diabetes in adults with slowly progressive beta-cell failure might be a more adequate concept. Studies conducted to date show a clear genetic overlap between LADA and type 1 diabetes with a high risk conferred by variants in the human leukocyte antigen (HLA) region. In contrast, data from the limited number of studies on lifestyle factors available indicate that LADA may share several environmental risk factors with type 2 Diabetes Mellitus including overweight, physical inactivity, alcohol consumption (protective) and smoking. These factors are known to influence insulin sensitivity, suggesting that insulin resistance, in addition to insulin deficiency due to autoimmune destruction of the beta cells, may play a key role in the pathogenesis of LADA. Moreover, this implies that onset of LADA, similar to type 2 Diabetes Mellitus, to some extent could be prevented or postponed by lifestyle modification such as weight reduction and increased physical activity. ${ }^{[5-7]}$

Hence; the present study was undertaken association of birthweight, obesity and family history in the development of latent autoimmune diabetes in adults (LADA) and type II diabetes.The present study was conducted with the aim of assessing the association of birth-weight, obesity and family history in the development of latent autoimmune diabetes in adults (LADA) and type II diabetes.

\section{Subjects and Methods}

This is an observational study performed in the Department of General Medicine, Sri Shankaracharya Medical College, Bhilai, Durg, Chhattisgarh in the period of six months from January 2018 to June 2018.

Written consent was obtained from all the patients after explaining in detail the entire research protocol. Exclusion criteria for the present study included:

- Patients with history of any other systemic illness,

- Patients with any known drug allergy,

- Patients with history of presence of any malignant neoplasm

A total of 50 healthy controls, 50 type 2 diabetic and 50 patients with LADA were enrolled. Complete demographic details of all the patients were obtained. Clinical examination of all the patients was carried out and medical history of all the patients was obtained. Detailed medical history and family history of all the patients was recorded separately. A Performa was made and complete anthropometric parameters were recorded. Body mass index (BMI) was calculated. All the results were recorded in Microsoft excel sheet and was analysed by SPSS software. Chi- square test, ANOVA and unpaired $t$ test was used for assessing the level of significance. p- value of less than 0.05 was taken as significant.

\section{Results}

In the present study, a total of 50 healthy controls, 50 type 2 diabetic and 50 patients with LADA were enrolled. Mean age of the patients of the control group, type 2 diabetic group and the LADA group was found to be 52.6 years, 55.4 years and 57.1 years respectively. Mean BMI of the patients of the control group, type 2 diabetic group and the LADA group was found to be $24.8 \mathrm{Kg} / \mathrm{m}^{2}, 32.1 \mathrm{Kg} / \mathrm{m}^{2}$ and $29.2 \mathrm{Kg} / \mathrm{m}^{2}$ respectively.

In the present study, while assessing association of birthweight in the development of latent autoimmune diabetes in adults (LADA) and type 2 Diabetes Mellitus; it was observed that significantly higher proportion of patients of the diabetic group and the LADA group had low birth-weight in comparison to the patients of the control group. In the present study, while assessing association of family history of diabetes in the development of latent autoimmune diabetes in adults (LADA) and type 2 Diabetes Mellitus; it was observed that significantly higher proportion of patients of the diabetic group and the LADA group had positive family history of diabetes in comparison to the patients of the control group. In the present study, while assessing association of obesity in the development of latent autoimmune diabetes in adults (LADA) and type 2 Diabetes Mellitus; it was observed that mean BMI of the patients of the diabetic group and the LADA group was significantly higher in comparison to the patients of the control group.

Table 1: Demographic data

\begin{tabular}{|l|l|l|l|}
\hline Parameter & Controls & T2DM & LADA \\
\hline Number of subjects & 50 & 50 & 50 \\
\hline Males $(\%)$ & 54 & 60 & 56 \\
\hline Mean age (years) & 52.6 & 55.4 & 57.1 \\
\hline Mean BMI $\left(\mathrm{Kg} / \mathrm{m}^{2}\right)$ & 24.8 & 32.1 & 29.2 \\
\hline
\end{tabular}

Table 2: Association of birth-weight in the development of latent autoimmune diabetes in adults (LADA) and type 2 Diabetes Mellitus

\begin{tabular}{|l|l|l|l|}
\hline Parameter & Controls & $\begin{array}{l}\text { Type 2 } \\
\text { diabetic }\end{array}$ & LADA \\
\hline Low birth-weight $(<3 \mathrm{Kg})(\%)$ & 12 & 26 & 24 \\
\hline Mean birth weight $(\mathrm{Kg})$ & 3.52 & 3.21 & 3.28 \\
\hline $\begin{array}{l}\text { p- value for Controls Versus Type } \\
\text { 2 diabetic }\end{array}$ & 0.02 (Significant) \\
\hline $\begin{array}{l}\text { p- value for Controls versus } \\
\text { LADA }\end{array}$ & 0.00 (Significant) \\
\hline $\begin{array}{l}\text { p- value for Type 2 diabetic } \\
\text { versus LADA }\end{array}$ & 0.34 (Non- Significant) \\
\hline
\end{tabular}

Table 3: Association of family history in the development of latent autoimmune diabetes in adults (LADA) and type 2 Diabetes Mellitus

\begin{tabular}{|l|l|l|l|}
\hline Parameter & Controls & T2DM & LADA \\
\hline $\begin{array}{l}\text { First degree positive family history } \\
\text { of diabetes }(\%)\end{array}$ & 20 & 46 & 42 \\
\hline $\begin{array}{l}\text { p- value for Controls Versus Type } \\
2 \text { diabetic }\end{array}$ & 0.02 (Significant) \\
\hline p- value for Controls versus LADA & 0.01 (Significant) \\
\hline $\begin{array}{l}\text { p- value for Type 2 diabetic } \\
\text { versus LADA }\end{array}$ & 0.28 (Non- Significant) \\
\hline
\end{tabular}


Table 4: Association of obesity in the development of latent autoimmune diabetes in adults (LADA) and type 2 Diabetes Mellitus

\begin{tabular}{|l|l|l|l|}
\hline Parameter & Controls & $\begin{array}{l}\text { Type 2 } \\
\text { diabetic }\end{array}$ & LADA \\
\hline Mean BMI $\left(\mathrm{Kg} / \mathrm{m}^{2}\right)$ & 24.8 & 32.1 & 29.2 \\
\hline $\begin{array}{l}\text { p- value for Controls } \\
\text { Versus Type 2 diabetic }\end{array}$ & 0.00 (Significant) \\
\hline $\begin{array}{l}\text { p- value for Controls } \\
\text { versus LADA }\end{array}$ & 0.00 (Significant) \\
\hline $\begin{array}{l}\text { p- value for Type 2 } \\
\text { diabetic versus } \\
\text { LADA }\end{array}$ & 0.75 (Non- Significant) \\
\hline
\end{tabular}

\section{Discussion}

Most epidemiological studies suggest that adult-onset autoimmune diabetes is not rare as previously reported. Indeed, data collected from Italian registries show that the incidence of T1DM in subjects aged 30 to 49 years is similar to that of adolescents aged 15 to 19 years. According to these data, studies among Caucasians from Northern Europe reported that approximately $40 \%$ of T1DM cases occur in people older than 30 years of age and that the real incidence of this condition in subjects aged 15 to 34 years is up to three times higher than previously reported. Data reported in LADA show that this is the most frequent form of adultonset autoimmune diabetes and may account for $2 \%$ to $12 \%$ of all cases of diabetes in adult population. Moreover, multicentre studies carried out in Europe, Asia, and North America, reported that $4 \%$ to $14 \%$ of patients diagnosed with T2DM are positive for T1DM associated autoantibodies which are diagnostic for LADA. However, the prevalence of LADA seems to vary between different countries and populations, probably due to differences in study design and inclusion criteria, as well as different life-style and ethnicity.[8 ${ }^{-11]}$ Hence; the present study was undertaken association of birth-weight, obesity and family history in the development of latent autoimmune diabetes in adults (LADA) and type II diabetes.

In the present study, a total of 50 healthy controls, 50 type 2 diabetic and 50 patients with LADA were enrolled. Mean age of the patients of the control group, type 2 diabetic group and the LADA group was found to be 52.6 years, 55.4 years and 57.1 years respectively. Mean BMI of the patients of the control group, type 2 diabetic group and the LADA group was found to be $24.8 \mathrm{Kg} / \mathrm{m}^{2}, 32.1 \mathrm{Kg} / \mathrm{m}^{2}$ and $29.2 \mathrm{Kg} / \mathrm{m}^{2}$ respectively. While assessing association of birth-weight in the development of latent autoimmune diabetes in adults (LADA) and type 2 Diabetes Mellitus; it was observed that significantly higher proportion of patients of the diabetic group and the LADA group had low birth-weight in comparison to the patients of the control group. Strong support for a role of environmental factors in the etiology of autoimmune diabetes is provided by the world wide rise in incidence of type 1 diabetes in children, which purposely reflects an increasingly diabetogenic environment rather than changes in the genetic makeup of the population. Still, the environmental triggers of autoimmunity and type 1 Diabetes have proved difficult to map. Associations with a number of lifestyle factors have been reported, including exposure to enterovirus, several dietary factors, weight gain and psychological stress. Nevertheless, attempts to replicate findings across studies have often failed and intervention studies have been largely unsuccessful in preventing type 1 diabetes in children. ${ }^{[12-14]}$ More is known about the etiology of type 2 Diabetes Mellitus; the risk is closely linked to a number of unhealthy lifestyle factors and among those, excess weight is the strongest risk factor; obesity is associated with a seven-fold increased risk according to a meta-analysis based on 18 prospective cohort studies. Low birth weight, purposely reflecting fetal malnutrition, is also associated with an increased risk of type 2 Diabetes Mellitus. In contrast, physical activity is associated with a reduced risk, whereas sedentary time and hours of TV viewing is positively associated with incidence of type 2 Diabetes Mellitus. ${ }^{[15-18]}$

In the present study, while assessing association of family history of diabetes in the development of latent autoimmune diabetes in adults (LADA) and type 2 Diabetes Mellitus; it was observed that significantly higher proportion of patients of the diabetic group and the LADA group had positive family history of diabetes in comparison to the patients of the control group. A potential relationship with excessive weight and LADA may depend on genetic susceptibility. Few studies have investigated gene-overweight interaction in relation to autoimmune diabetes. However, a Swedish study found that type 1 diabetes in children with low-risk HLA DQ haplotypes was associated with higher prevalence of overweight/obesity in a synergistic manner. Further support came from a study of multiple sclerosis in which the authors reported a striking additive interaction between obesity and the high risk HLADRB $1 * 15$ genotype. For type 2 Diabetes Mellitus, large-scale studies have found interaction between a genetic risk score, BMI status and waist circumference. Studies of specific genotypes are scarce. Nevertheless, a Chinese study recently reported a strong interaction between TCF7L2 risk genotype (rs290487) and BMI status /waist circumference in relation to type 2 Diabetes Mellitus risk. The FTO gene is also interesting as the risk variants seem to modify eating behaviour and body composition, at the same time, the risk of type 2 Diabetes Mellitus attenuates with physical activity. Studies of family history further support a strong gene-overweight interaction in the aetiology of type 2 Diabetes Mellitus. ${ }^{[10-19]}$

In the present study, while assessing association of obesity in the development of latent autoimmune diabetes in adults (LADA) and type 2 Diabetes Mellitus; it was observed that mean BMI of the patients of the diabetic group and the LADA group was significantly higher in comparison to the patients of the control group.Reports on family history in LADA are scarce but cross-sectional studies indicate a high prevalence. A 4-fold increased risk in those with a family history of any type of diabetes was found in a previous study, whereas the risk was increased 2-fold in the Finnish Botnia study. Because LADA is suggested to be hybrid form of diabetes, which is also supported by evidence from some genetic studies, family history of both type 1 and type 2 Diabetes Mellitus may potentially promote LADA. Findings of a few smaller studies support this hypothesis. Furthermore, prospective data from the Botnia study found that a mix of both forms of diabetes in the family was associated with a 2-fold increased risk of non-insulin requiring diabetes. However, the relative importance of family history of type 1 versus type 2 Diabetes Mellitus in the aetiology of LADA has not been explored. ${ }^{[16-20]}$ 


\section{Conclusion}

From the above results, the authors conclude that low birth weight, obesity and positive family history of diabetes are important risk factors in the development of latent autoimmune diabetes in adults (LADA) and type II diabetes. However; further studies are recommended.

\section{References}

1. Lampasona V, Petrone A, Tiberti C, Capizzi M, Spoletini M, di Pietro $\mathrm{S}$, et al. Zinc transporter 8 antibodies complement GAD and IA-2 antibodies in the identification and characterization of adult-onset autoimmune diabetes: Non Insulin Requiring Autoimmune Diabetes (NIRAD) 4. Diabetes Care. 2010;33:104-108.

2. Leslie RD, Kolb H, Schloot NC, Buzzetti R, Mauricio D, De Leiva A, et al. Diabetes classification: grey zones, sound and smoke: Action LADA 1. Diabetes Metab Res Rev. 2008;24:511-519.

3. Clare-Salzler MJ, Tobin AJ, Kaufman DLO. Glutamate decarboxylase: an autoantigen in IDDM. Diabetes Care. 1992;15(1):132-135.

4. Wild S, Roglic G, Green A, Sicree R, King H. Global prevalence of diabetes: estimates for the year 2000 and projections for 2030. Diabetes Care. 2004;27(5):1047-1053.

5. Basavanagowdappa H, Prabhakar AK, Prasannaraj P, Gurudev KC, Suma V. Study of prevalence of diabetes mellitus and impaired fasting glucose in a rural population. International Journal of Diabetes in Developing Countries. 2005; 25 (4): 98- 101.

6. Fourlanos S, Dotta F, Greenbaum CJ, et al. Latent autoimmune diabetes in adults (LADA) should be less latent. Diabetologia. 2005;48(11):2206-2212.

7. Hawa MI, Thivolet C, Mauricio D, Alemanno I, Cipponeri E, Collier $\mathrm{D}$, et al. Metabolic syndrome and autoimmune diabetes: Action LADA 3. Diabetes Care. 2009;32:160-164.

8. Mollo A, Hernandez M, Marsal JR, Esquerda A, Rius F, Blanco-Vaca F, et al. Latent autoimmune diabetes in adults is perched between type 1 and type 2: evidence from adults in one region of Spain. Diabetes Metab Res Rev. 2013;29:446-451.

9. Petrone A, Suraci C, Capizzi M, Giaccari A, Bosi E, Tiberti C, et al. The protein tyrosine phosphatase nonreceptor 22 (PTPN22) is associated with high GAD antibody titer in Latent autoimmune diabetes in adults: Non Insulin Requiring Autoimmune Diabetes (NIRAD) Study 3. Diabetes Care. 2008;31:534-538.

10. Carlsson A, Kockum I, Lindblad B, Engleson L, Nilsson A, Forsander $\mathrm{G}$, et al. Low risk HLA-DQ and increased body mass index in newly diagnosed type 1 diabetes children in the Better Diabetes Diagnosis study in Sweden. Int J Obes (Lond) 2012;36(5):718-24.

11. Hedstrom AK, Lima Bomfim I, Barcellos L, Gianfrancesco M, Schaefer C, Kockum I, et al. Interaction between adolescent obesity and HLA risk genes in the etiology of mul tiple sclerosis. Neurology 2014;82(10):865- 72 .

12. Cornelis MC, Qi L, Zhang C, Kraft P, Manson J, Cai T, et al. Joint effects of common genetic variants on the risk for type 2 Diabetes Mellitus in U.S. men and women of European ancestry. Ann Intern Med 2009;150(8):541-50.

13. Langenberg C, Sharp SJ, Franks PW, Scott RA, Deloukas P, Forouhi NG, et al. Gene-lifestyle interaction and type 2 Diabetes Mellitus: the EPIC interact case-cohort study. PLoS Med 2014;11(5):e1001647.

14. Li L, Wang J, Ping Z, Li Y, Wang C, Shi Y, et al. Interaction analysis of gene variants of TCF7L2 and body mass index and waist circumference on type 2 Diabetes Mellitus. Clin Nutr 2019.

15. Kilpelainen TO, Qi L, Brage S, Sharp SJ, Sonestedt E, Demerath E, et al.

16. Physical activity attenuates the influence of $F T O$ variants on obesity risk: a meta-analysis of 218,166 adults and 19,268 children. PLoS Med 2011;8(11):e1001116.

17. Andreasen CH, Stender -Petersen KL, Mogensen MS, Torekov SS, Wegner L, Andersen G, et al. Low physical activity accentuates the effect of the FTO rs9939609 polymorphism on body fat accumulation. Diabetes 2008;57(1):95-101.

18. Morris RD, Rimm DL, Hartz AJ, Kalkhoff RK, Rimm AA. Obesity and heredity in the etiology of non-insulin-dependent diabetes mellitus in 32,662 adult white women. Am J Epidemiol 1989;130(1):112-21.

19. Sargeant LA, Wareham NJ, Khaw KT. Family history of diabetes identifies a group at increased risk for the metabolic consequences of obesity and physical inactivity in EPIC-Norfolk: a population-based study. The European Prospective Investigation into Cancer. Int J Obes Relat Metab Disord 2000;24(10):1333-9.

20. Lundgren VM, Isomaa B, Lyssenko V, Laurila E, Korhonen P, GroopLC, et al. GAD antibody positivity predicts type 2 Diabetes Mellitus in an adult population. Diabetes 2010;59(2):416-22.

Copyright: () the author(s), 2019. It is an open-access article distributed under the terms of the Creative Commons Attribution License (CC BY 4.0), which permits authors to retain ownership of the copyright for their content, and allow anyone to download, reuse, reprint, modify, distribute and/or copy the content as long as the original authors and source are cited.

How to cite this article: Verma S, Sharma S, Rangari P. Association of Birth-Weight, Obesity and Family History in the Development of Latent Autoimmune Diabetes in Adults (LADA) and Type 2 Diabetes Mellitus. Acad. J Med. 2019;2(2):182-85.

DOI: dx.doi.org/10.21276/ajm.2019.2.2.47

Source of Support: Nil, Conflict of Interest: None declared. 